\title{
Design and Research of Active Heave Compensation System Based on Laser Ranging Sensor
}

\author{
Chongyang Han \\ Shanghai Maritime University, Shanghai, China \\ Email:1012827175@qq.com
}

How to cite this paper: Han, C.Y. (2020) Design and Research of Active Heave Compensation System Based on Laser Ranging Sensor. World Journal of Engineering and Technology, 8, 13-18.

https://doi.org/10.4236/wjet.2020.81002

Received: September 16, 2019

Accepted: December 8, 2019

Published: December 11, 2019

Copyright ( 2020 by author(s) and Scientific Research Publishing Inc. This work is licensed under the Creative Commons Attribution International License (CC BY 4.0).

http://creativecommons.org/licenses/by/4.0/

\begin{abstract}
Marine resource exploitation and marine cargo transportation were increasingly frequent. Due to the impact of the marine environment, ships or platforms were affected. In this paper, a servo electric cylinder was used as a wave compensation actuator to design a wave compensation system. The laser sensor was used to measure the displacement in the direction of the heave platform, and the obtained displacement was applied to the wave compensation in the heave direction to verify the feasibility of the compensation system.
\end{abstract}

\section{Keywords}

Wave Compensation, Laser Ranging Sensor, Heave Stability Platform

\section{Introduction}

With the rapid development of marine logistics trade, the status of marine cranes in sea transportation is getting higher and higher. However, due to the complicated environment of offshore operations, the control of marine cranes is influenced by water flow and wind power, which results in heave phenomenon of the marine crane platform. As shown in Figure 1, the wind power platform requires stable environment, otherwise it will cause a lot of losses [1]. In this paper, a heave compensation platform based on laser ranging sensor is designed to ensure the safety of the crane and reduce the damage caused by wave heave. The six-degree-of-freedom platform will be used to simulate the movement of the crane platform in the direction of heave, and the laser ranging sensor is used as the sensor for the attitude measurement of the six-degree-of-freedom platform. Under laboratory conditions, the displacement of the six-degree-of-freedom 


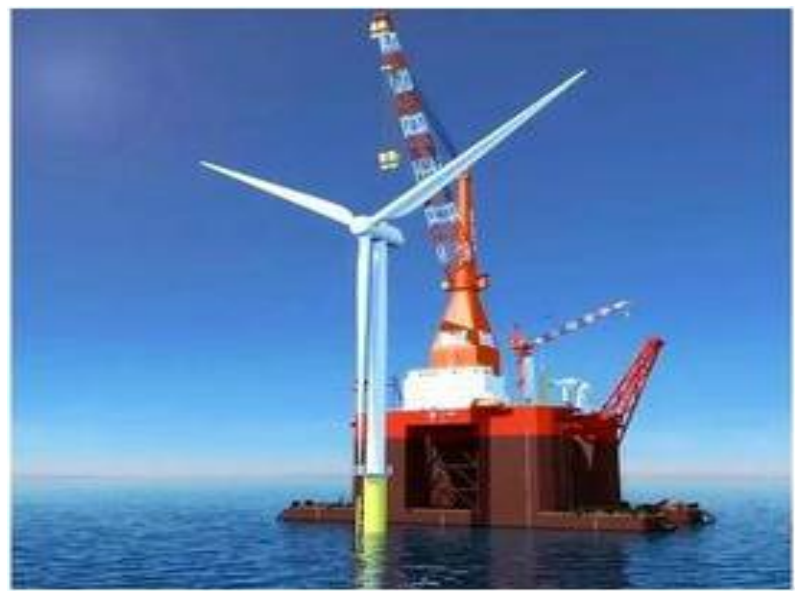

Figure 1. Wind power platform.

platform can be directly obtained by the laser ranging sensor, and the displacement compensation system design is carried out.

\section{The Principle of Wave Compensation}

When the six-degree-of-freedom platform reciprocates in the direction of the heave, the compensation platform follows the action. The laser sensor under the six-degree-of-freedom platform provides real-time, high-precision displacement of the six-degree-of-freedom platform. The sensor outputs an analog voltage signal that is transmitted to the data acquisition card. The collected data is transcoded, stored and calculated by a PC. According to the position of the six-degree-of-freedom platform set in the previous period [2], the amount of change in the attitude of the platform in the heave direction can be obtained. The amount of change is the amount that the compensation platform needs to compensate, and this amount of change is converted into a pulse and transmitted to the motion control card. The motion control card sends a pulse + direction command to the servo drive via internal calculation. The pulse + direction command is converted into a control voltage by the servo driver, in order to control the servo motor. The compensation platform moves quickly in the opposite direction under the action of the electric cylinder to ensure that the compensation platform is stable at the set position. The encoder on the servo motor returns current feedback and speed feedback in real time to form current loop, speed loop and position loop control [3].

According to the principle of wave compensation, a wave compensation system is built. Figure 2 shows the hardware structure of the wave compensation system based on the laser ranging sensor. Table 1 shows the names and quantities of the main equipment instruments of the wave compensation system.

\section{Laser Sensor}

The heave compensation system selects two kinds of laser ranging sensors under the experimental conditions: HG-C1400 laser ranging sensor and IfmO1D100 


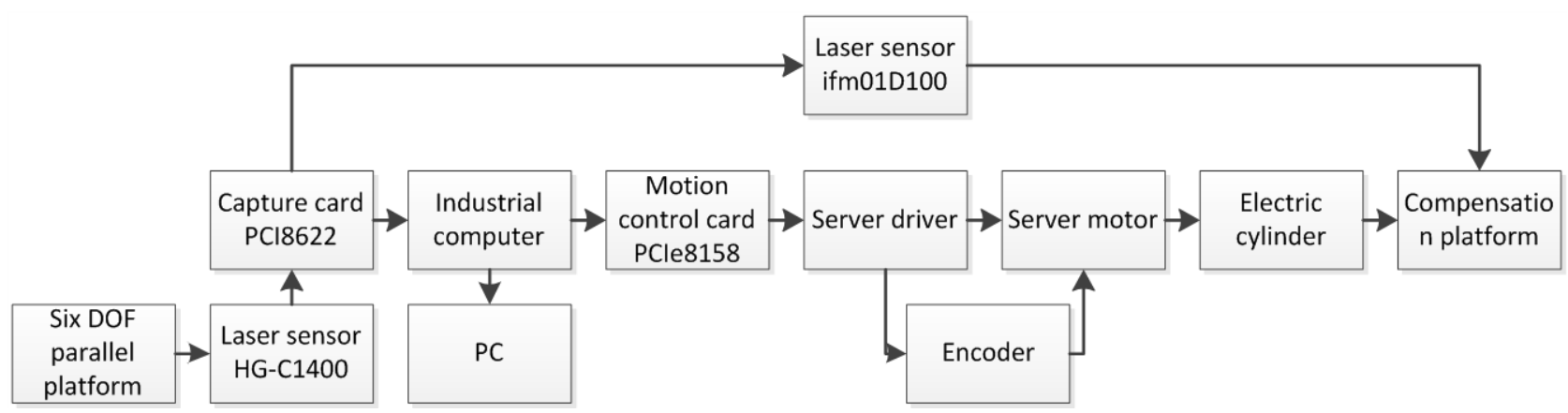

Figure 2. Structure of wave compensation system.

Table 1. Main equipment of wave compensation system.

\begin{tabular}{cc}
\hline Equipment & Quantities \\
\hline Laser sensor HG-C1400 & 1 \\
Capture card & 1 \\
PC + Industrial computer & 1 \\
Motion control card & 1 \\
Sever driver & 1 \\
Sever motor & 1 \\
Laser sensor IfmO1D100 & 1 \\
\hline
\end{tabular}

laser ranging sensor. The accuracy of the former is higher than that of the latter. The HG-C100 is used for six-degree-of-freedom platform attitude measurement, and the IfmO1D100 is used for compensation accuracy measurement. The laser distance measuring sensor is composed of a laser, a laser detector and a measuring circuit, and can realize non-contact measurement, high speed, high precision, large measuring range, strong anti-light and strong electronic interference capability. By recording and processing, the time between when the light pulse is emitted and when it is received can be obtained, and then the distance can be calculated from the speed of the light [4].

Figure 3 shows the HG-C1400 laser ranging sensor. The sensor outputs the displacement of the measured object through an analog signal. The output can be either voltage $(0-5 \mathrm{~V})$ or current $(4-20 \mathrm{~mA})$. In the compensation system, the voltage is selected as the output form. According to the parameters of HG-C1400, the output voltage range is $0-5 \mathrm{~V}$, and the corresponding distance range is $\pm 200 \mathrm{~mm}$. It can be seen that the distance corresponding to $2500 \mathrm{mv}$ is 0 $\mathrm{mm}, 5 \mathrm{~V}$ corresponds to $200 \mathrm{~mm}$, and $0 \mathrm{~V}$ corresponds to $-200 \mathrm{~mm}$. The laser ranging sensor sensitivity $K_{j 1}=0.08 \mathrm{~mm} / \mathrm{mv}$ can be obtained. When the output voltage $U_{1}$ is measured, the analog voltage can be converted into the distance $S_{1}$ by the following formula [5].

$$
S_{1}=\left(U_{1}-2500\right) \times 0.08
$$

Figure 4 shows the IfmO1D100 laser measurement and control sensor, which is less accurate than the HG-C1400 laser range sensor. The measuring distance is 


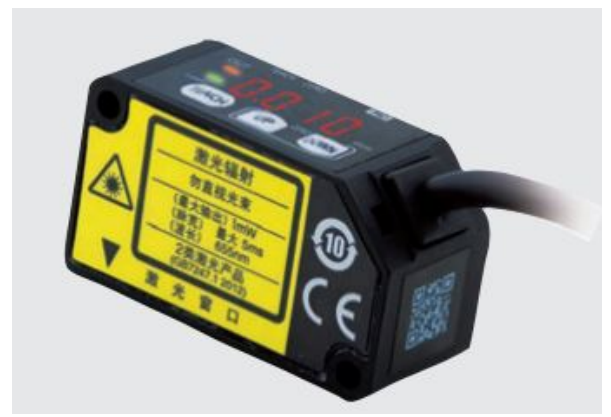

Figure 3. HG-C1400.

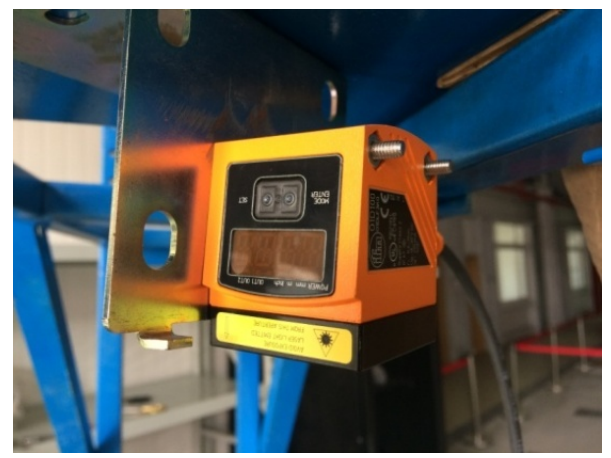

Figure 4. Ifm O1D100.

$200-1000 \mathrm{~mm}$, and the measuring accuracy is $\pm 15 \mathrm{~mm}$. The O1D100 can set the measurement range. The measurement range set here is $0-2000 \mathrm{~mm}$, and the corresponding output voltage is $0-10 \mathrm{~V}$. Thereby, the sensitivity of the laser ranging sensor $K_{f 2}=0.2 \mathrm{~mm} / \mathrm{mv}$ can be obtained. When the output voltage $U_{2}$ $\mathrm{mv}$ is measured, the analog voltage can be converted into the distance S_2 by the following formula.

$$
S_{2}=U_{2} \times 0.2
$$

The HG-C1400 sensor is used to measure the platform's heave displacement, and the IfmO1D100 is used to measure the compensation platform compensation effect.

Both sensors need to be fixed in a relatively stable position, bolted in the laboratory to ensure that the beam is vertical, so that the measurement accuracy can be guaranteed.

\section{Compensation Effect}

The six-degree-of-freedom platform is tested according to the period $\mathrm{T}=10 \mathrm{~s}$, the amplitude $\mathrm{F}=30 \mathrm{~mm}$ and the period $\mathrm{T}=10 \mathrm{~s}$, and the amplitude $\mathrm{F}=50 \mathrm{~mm}$, to verify the effectiveness of the compensation system. Figure 5 is a compensation effect diagram of the period $\mathrm{T}=10 \mathrm{~s}$ and the amplitude $\mathrm{F}=30 \mathrm{~mm}$, and Figure 6 is a compensation effect diagram of the period $\mathrm{T}=10 \mathrm{~s}$ and the amplitude $\mathrm{F}=5$.

It can be seen from the figure that when the six-degree-of-freedom platform moves according to the period $\mathrm{T}=10 \mathrm{~s}$ and the amplitude $\mathrm{F}=30 \mathrm{~mm}$, the 


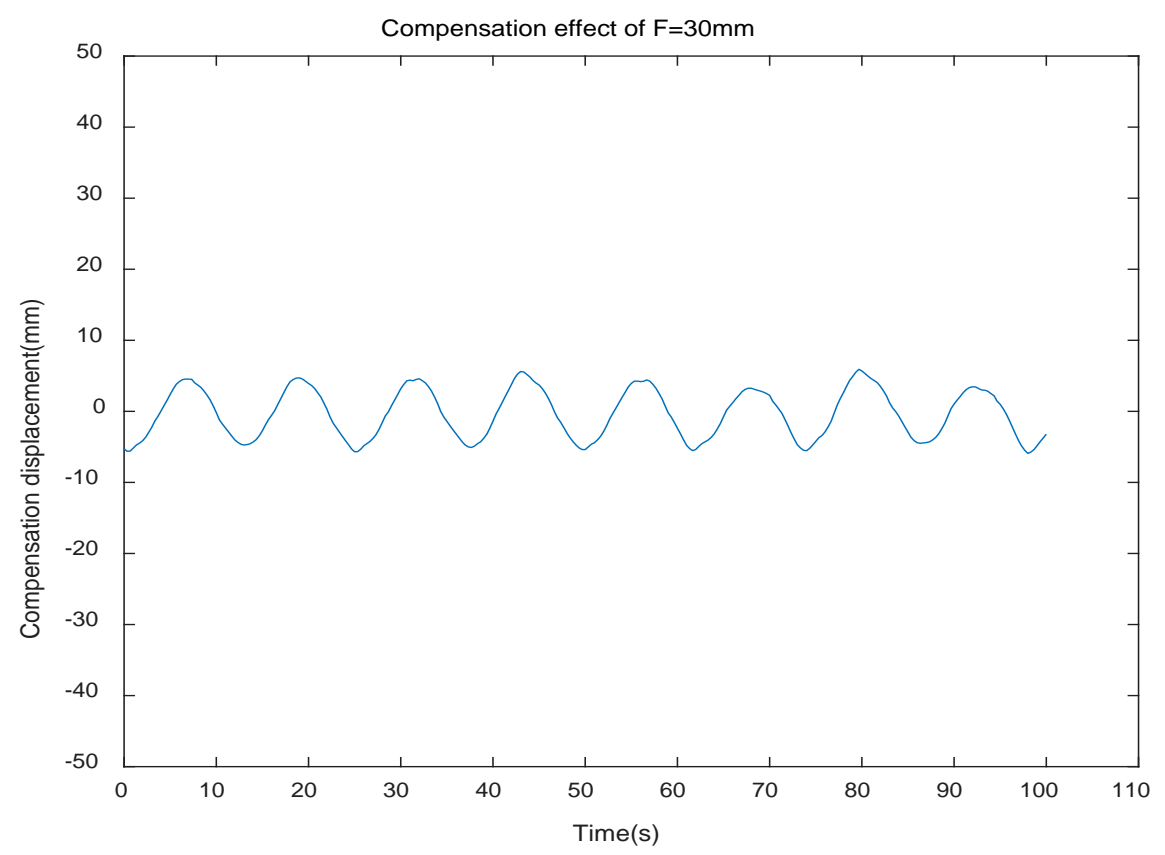

Figure 5. Compensation effect of $\mathrm{F}=30 \mathrm{~mm}$.

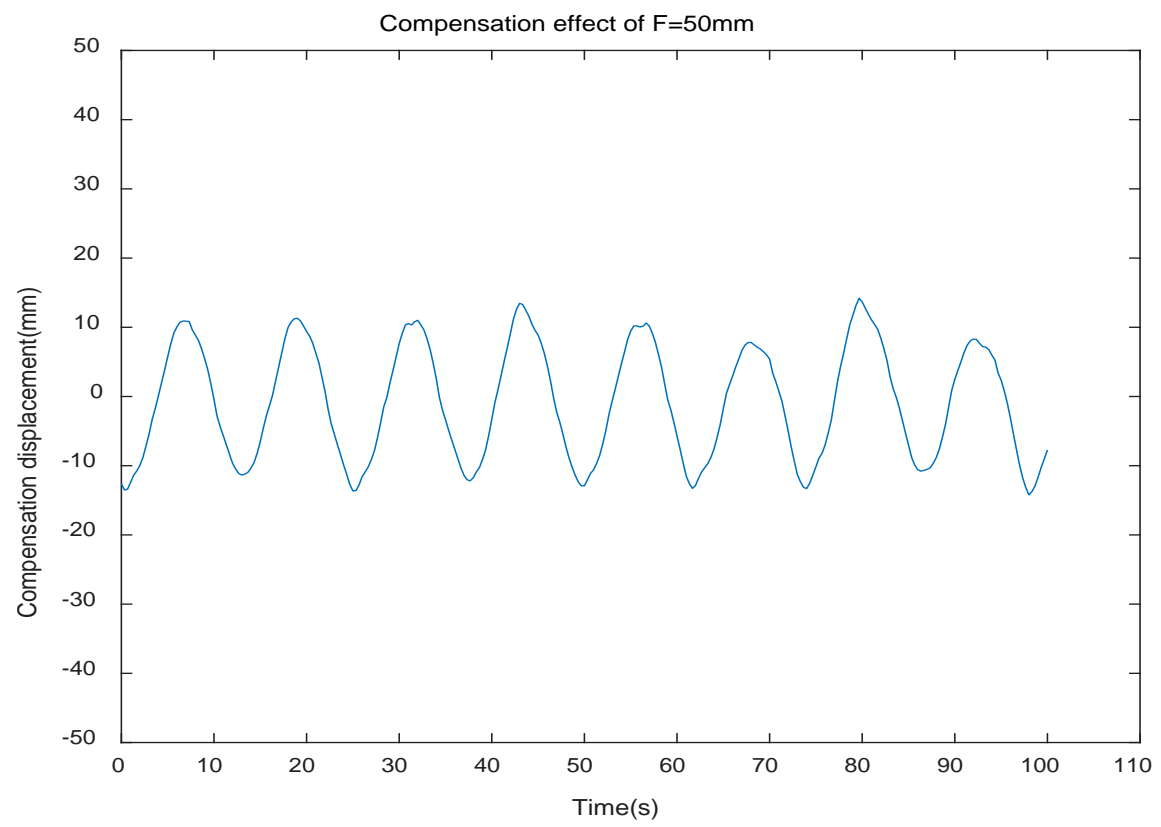

Figure 6. Compensation effect of $\mathrm{F}=50 \mathrm{~mm}$.

compensation platform is stable between $\pm 5 \mathrm{~mm}$ and the steady-state error is $17 \%$. When the six-degree-of-freedom platform period is $\mathrm{T}=10 \mathrm{~s}$ and the amplitude is $\mathrm{F}=50 \mathrm{~mm}$, the compensation platform is stable between $\pm 12 \mathrm{~mm}$ and the steady-state error is $24 \%$.

\section{Conclusions}

1) The electric cylinder is feasible as a compensation actuator and achieves a 
good compensation effect;

2) The six-degree-of-freedom platform has the same cycle, the amplitude increases, and the compensation effect of the wave compensation platform becomes worse.

By making the six-degree-of-freedom platform move by $\mathrm{T}=10 \mathrm{~s}, \mathrm{~F}=30 \mathrm{~mm}$ and $\mathrm{T}=10 \mathrm{~s}, \mathrm{~F}=50 \mathrm{~mm}$ respectively, the effectiveness of the compensation system is verified, which establishes the foundation for the next experiment.

Although some work has achieved certain results, there are still some shortcomings in this paper, and further work can be improved in the direction of predictive delay processing.

1) At present, the wave excitation is simplified, and the simple sinusoidal motion is used for wave simulation, which is still far from the actual application;

2) The cause of the current steady-state error is due to the delay of the device characteristics and control signals.

\section{Conflicts of Interest}

The author declares no conflicts of interest regarding the publication of this paper.

\section{References}

[1] Korde, U.A. (1998) Active Heave Compensation on Drill-Ships in Irregular Waves. Ocean Engineering, 25, 541-561. https://doi.org/10.1016/S0029-8018(97)00028-0

[2] Kim, D., Chung, W. and Youm, Y. (2002) Analytic Singularity Expression for 6-DOF Stewart Platform-Type Parallel Manipulators. IEEE/RSJ International Conference on Intelligent Robots \& Systems.

[3] Neupert, J., Mahl, T., Haessig, B., et al. (2008) A Heave Compensation Approach for Offshore Cranes. American Control Conference, Seattle, 11-13 June 2008, 538-543. https://doi.org/10.1109/ACC.2008.4586547

[4] Diels, J. and Arissian, L. (2011) Laser Sensors. Lasers: The Power and Precision of Light. https://doi.org/10.1002/9783527640034

[5] Yang, L.-H., Liu, J., Wang, Y.-M., et al. (2018) New Activation Weight Calculation and Parameter Optimization for Extended Belief Rule-Based System Based on Sensitivity Analysis. Knowledge and Information Systems, 60, 837-878. https://doi.org/10.1007/s10115-018-1211-0 